\title{
Permodelan Perubahan Penggunaan Lahan Berbasis Cellular Automata dan Sistem Informasi Geografis dengan Menggunakan LanduseSim
}

\author{
Nursakti Adhi Pratomoatmojo \\ Departemen Perencanaan Wilayah dan Kota, Fakultas Arsitektur, Desain dan Perencanaan \\ Institut Teknologi Sepuluh Nopember \\ e-mail: pratomoatmojo@urplan.its.ac.id
}

\begin{abstract}
Abstrak - Penelitian ini bertujuan untuk menjelaskan melalui proses terkait metode pemodelan perubahan penggunaan lahan (land use change) berbasis Cellular Automata menggunakan perangkat lunak LanduseSim di Kota Pekalongan. Adapun maksud dalam penelitian ini adalah untuk menjelaskan metode Cellular Automata yang digunakan dalam pemodelan yang bersifat eksperimental. Penggunaan lahan yang disimulasikan untuk tumbuh pada wilayah penelitian ini terdiri dari dua kelas; kelas Industri-Transportasi dan kelas Permukiman. Faktorfaktor pendorong yang digunakan pada penelitian ini terbatas untuk ujicoba beserta bobot yang ditetapkan sebagai data hipotesis. Kota Pekalongan dipilih sebagai lokasi studi pemodelan penggunaan lahan. Pada penelitian ini, hasil simulasi dengan pendekatan Cellular Automata dengan data raster resolusi rendah, menunjukkan bahwa penggunaan pada tingkat kedetailan 1 Hektar masih layak dan dapat dilakukan untuk memberikan gambaran prediksi pada skala ketelitian tertentu.
\end{abstract}

Kata Kunci-Cellular Automata, LanduseSim, Land use change, Sistem Informasi Geografis

\section{PENDAHULUAN}

$\mathrm{F}$ ENOMENA perkembangan kota selalu menerima perhatian yang besar dalam beberapa dekade, terutama kaitannya dengan kemampuannya merubah komposisi landskap (10). Perkembangan kota ditandai oleh adanya peningkatan intensitas perubahan lahan seperti konversi lahan non-terbangun menjadi lahan terbangun. Perubahan lahan merupakan proses yang kompleks dikarenakan banyak interaksi dan faktor yang mempengaruhinya dari berbagai tingkat skala, ruang dan waktu (4)(5)(15).

Model perkembangan kota masih banyak yang dilakukan secara non-spasial dimana pendekatan tersebut diperlukan untuk menghasilkan skenario kebijakan dalam perencanaan wilayah (6). Dalam topik perubahan penggunaan lahan, cellular automata (CA) terbukti sebagai metode unggulan untuk memprediksi penggunaan lahan secara spasial. Perkembangan CA. Cellular automata membuktikan menjadi metode yang sangat sesuai untuk prediksi dinamika penggunaan lahan melalui proses simulasi spasial. Metode CA yang berasal dari ilmu matematika sangat baik dalam menirukan spasial proses yang kompleks (Wolfram, 1984). Aplikasi CA diperkenalkan pada pemodelan geografis oleh Tobler (1979) dan mulai berkembang penerapannya ke pemodelan bentuk kota (Batty, 1997), perkembangan fisik perkotaan (Clarke et al., 1997;
Coucleis, 1997), perencanaan land use (Wu, 1998; Li and Yeh, 2000), dan perencanaan wilayah dan kota (Engelen et al., 1999; White and Engelen, 2000). CA Model mampu mengontrol spatial pattern change melalui aturan perubahan yang melibatkan konfigurasi ketetanggaan dan peta potensi transisi (White and Engelen, 1993; Wu, 2002; Li and Yeh, 2000; Li and Yeh, 2004; Thomas and Laurence, 2006; Liu et al., 2007). Beberapa CA model juga telah dikembangkan dengan mengkombinasikan skenario hambatan agar lebih sesuai dengan kebutuhan perencanaan land use, seperti yang dilakukan oleh Li and Yeh (2000), He et al. (2008), Mitsova et al. (2011), Long et al. (2012a, 2012b), dan Fulsang et al. (2013).

Beberapa perangkat lunak yang dapat melakukan pemodelan perubahan lahan secara spasial berbasis Cellular Automata antara lain seperti Idrisi (dikembangkan oleh Clark Labs), SLEUTH, Metronamica (dikembangkan oleh Risk University), dan Clue-S (dikembangkan oleh Peter Verberg (29)). Namun pada umumnya perangkat lunak tersebut berorientasi pada kemampuan untuk memprediksi perubahan lahan berbasis trend daripada perubahan lahan berbasis skenario atau target. Hal ini menjadi salah satu kelemahan aplikasi-aplikasi tersebut dikarenan mekanisme trend menjadi kurang relevan untuk kegiatan perencanaan wilayah dan kota, seperti penyusunan dokumen tata ruang dimana banyak opsi perencanaan pembangunan infrastruktur yang perlu ditetapkan dalam rencana tata ruang.

Termasuk perlunya banyak data pendukung dengan mempertimbangkan rencana infrastruktur kedalam pemodelan yang dilakukan termasuk pada pendekatan target atau skenario. LanduseSim yang dikembangkan oleh Nursakti Adhi Pratomoatmojo, menjadi salah satu perangkat lunak yang memiliki kelebihan dibanding aplikasi lain terutama dalam mengeksekusi pemodelan berbasis target atau skenario (22).

Penelitian ini berupaya untuk menunjukkan kemampuan LanduseSim sebagai salah satu alat analisis spasial dalam memprediksikan perubahan penggunaan lahan melalui proses simulasi berbasis sistem informasi geografis. Pada penelitian ini, Kota Pekalongan ditetapkan sebagai wilayah studi dalam proses pemodelan yang dilakukan. 


\section{METODE PENELITIAN}

\section{A. Tahapan Penelitian}

Tahap ini menjelaskan data dan metode pelaksanaan penelitian yang dilakukan. Pada studi ini, peta Kota Pekalongan tahun 2003 diproduksi dengan cara digitasi pada skala 1:5000 dari citra quickbird pada Google Earth yang sudah dipublikasi pada Pratomoatmojo (23) dan Marfai dkk (19). Peta yang didigitasi tersebut dikonversi menjadi peta raster terkait kebutuhan cellular automata, dengan resolusi 1 Hektar (100m x $100 \mathrm{~m})$ per sel raster sebagai satuan unit analisis yang dibutuhkan. Peta penggunaan lahan telah disesuaikan dengan LanduseSim-TE dengan limitasi 5 kelas penggunaan lahan. Adapun beberapa data lain yang digunakan sebagai faktor pendorong pertumbuhan pada simulasi proses, seperti penggunaan jaringan jalan berasal dari peta rupa bumi yang dihasilkan oleh BIG (Badan Informasi Geospasial Indonesia).

Pada penelitian ini software LanduseSim digunakan untuk melakukan simulasi perkembangan lahan di Kota Pekalongan dengan data resolusi rendah. LanduseSim menggunakan algoritma cellular automata untuk melakukan simulasi spasial berbasis SIG. LanduseSim selain itu menawarkan berbagai pendekatan yang mengijinkan pengguna mengkontrol semua faktor yang akan dimodelkan (12), seperti besaran sel yang diekspektasi untuk tumbuh, faktor pendorong, scenario termasuk implementasi zoning, scenario pembangunan infrastruktur fisik, simulasi multi-penggunaan lahan, dan simulasi perkembangan landuse baru. Cellular automata pada aplikasi LanduseSim berbeda dengan simulasi berbasis Markov-CA (23), dimana LanduseSim-CA input pertumbuhan dapat dilakukan dengan pendekatan apapun baik trend maupun target, sedangkan Markov-CA hanya dapat ditentukan dengan pertimbangan probabilitas. Simulasi pada LanduseSim bermula dengan proses ketetanggaan dimana proses ini mengolah peta yang diinput sebagai initial transition map, menjadi peta potensi transisi (transition potential map). Peta initial transition map sendiri dibangun dengan mekanisme overlay berbobot (weighted overlay) dan pendekatan SMCE (Spatial Multi Criteria Evaluation) dari beberapa peta kesesuaian.

Pada LanduseSim, Transition Potential Map menunjukkan arah perkembangan penggunaan lahan yang disimuasikan. Adapun peta potensi transisi dapat dihasilkan dengan rumus perhitungan sebagai berikut:

$$
T P_{i_{x, y}}=\sum_{z=0}^{n}\left(N_{i_{(z+n)_{x y}}} . T P_{i_{(z \rightarrow n)_{x y}}}\right)
$$

$$
T P_{i_{x, y}}=\begin{aligned}
& \text { Nilai peta transisi perubahan penggunaan lahan } \\
& \text { pada sel }(\mathrm{x}, \mathrm{y})(\text { operasi filter penjumlahan })
\end{aligned}
$$

$N_{i_{(z \rightarrow n)_{x, y}}}=$ Proses ketetanggaan dan akumulasinya dalam merubah nilai sel $(\mathrm{x}, \mathrm{y})$, sedangkan $\mathrm{n}$ adalah total tetangga yang diproses dalam mekanisme filtering.

$I T P_{i(z \rightarrow n)_{x}=}=$ Peta potensi awal (initial transition potential map) untuk penggunaan lahan i. Selain itu dapat juga dijelaskan sebagai peta kesesuaian suatu penggunaan lahan
Sebelum menjalankan formula diatas, perlu dibuat peta transisi terlebih dahulu. Peta transisi potential perkembangan dibuat dengan cara menggabungkan pendekatan multi-criteria evaluation (MCE), standarisasi dan sistem informasi geografis (32) yang kesemuanya digunakan untuk membuat peta transisi perubahan tiap penggunaan lahan. Peta transisi dihasilkan menggunakan modul Weighted Raster pada LanduseSim. Prosese Cellular Automata berproses secara iteratif tiap tahun simulasi dimana proses pertumbuhannya mengikuti peta transisi tiap penggunaan lahan yang diestimasikan untuk tumbuh. Pada LanduseSim, Cellular Automata proses mengikuti formula berikut ini (Persamaan 2):

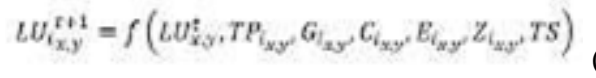

$$
\begin{aligned}
L U_{i_{x, y}}^{t+1}= & \text { Status penggunaan lahan i pada waktu t+1 pada } \\
& \text { sel (x,y). } \\
L U_{x, y}^{t}= & \text { Status penggunaan lahan i sebelum disimulasi } \\
& \text { (pada waktu t) pada sel }(\mathrm{x}, \mathrm{y}) . \\
T P_{i_{x, y}}= & \text { Peta potensi transisi penggunaan lahan i pada } \\
& \text { sel }(\mathrm{x}, \mathrm{y}) . \\
G_{i_{x, y}}= & \text { Jumlah sel yang diekspektasi tumbuh dari } \\
& \text { suatu jenis penggunaan lahan/tutupan lahan i } \\
& \text { pada waktu t+1 } \\
E_{i_{x, y}=}= & \text { Elastisitas perubahan penggunaan lahan } \\
& \text { menjadi kelas lahan lain yang akan menjadi } \\
& \text { kelas lahan i } \\
C_{i_{x, y}}= & \text { Lahan pembatas pertumbuhan yang tidak dapat } \\
& \text { dikonversi oleh kelas lahan i. Lahan ini juga } \\
& \text { dapat berupa zoning maupun lahan yang secara } \\
& \text { hierarki tidak dapat dirubah oleh kelas lahan } \\
& \text { tertentu }
\end{aligned}
$$

\begin{tabular}{|c|c|c|c|c|}
\hline Land Use & $\begin{array}{c}\text { Kode } \\
\text { LU }\end{array}$ & $\begin{array}{c}\text { Pertumbuhan } \\
\text { yang } \\
\text { diekspektasi }\end{array}$ & $\begin{array}{c}\text { Sel tumbuh } \\
(100 \mathrm{~m} \times 100 \mathrm{~m})\end{array}$ & $\begin{array}{l}\text { LU Pembatas } \\
\end{array}$ \\
\hline $\begin{array}{l}\text { Industri dan } \\
\text { Transportasi }\end{array}$ & 1 & $50 \mathrm{Ha}$ & $50 \mathrm{sel}$ & $\begin{array}{l}\text { (2) Ruang } \\
\text { Terbuka Hijau, } \\
\text { (3) Tubuh Air }\end{array}$ \\
\hline
\end{tabular}

\section{HASIL DAN PEMBAHASAN}

Proses cellular automata pada LanduseSim selain membutuhkan peta transisi untuk masing-masing penggunaan lahan juga membutuhkan target pertumbuhan yang ingin dicapai. Pada kasus ini digunakan data hipotesis dengan dua jenis penggunaan lahan yang diharapkan untuk tumbuh, yaitu kelas Industri dan Transportasi dan kelas Permukiman. Adapun rincian aturan transisi yang dikembangkan untuk simulasi cellular automata pada studi ini dapat dilihat pada tabel 1 .

Tabel 1.

Aturan transisi untuk land use yang diekspektasi tumbuh 


\begin{tabular}{llll}
\hline Permukiman & 3 & $700 \mathrm{Ha}$ & $700 \mathrm{sel}$
\end{tabular}

(1) industri dan transportasi (2) ruang terbuka hijau (3) tubuh air

\section{A. Pembentukan Peta Transisi Pertumbuhan Penggunaan Lahan}

Peta inisial potensi transisi pada perubahan lahan adalah hal yang sangat utama dimana basis pertumbuhan akan mengikuti nilai transisi tersebut untuk setiap penggunaan lahan. Pada studi ini, faktor aksesibilitas digunakan untuk menentukan perkembangan permukiman dan industri-transportasi. Proses standarisasi pada peta aksesibilitas pada LanduseSim menggunakan fuzzy set: liniear monotonically decreasing dimana nilai akan memiliki rentang antara 0 (nol) dan 1 (satu), dimana semakin jauh jarak aksesibilitasnya akan memiliki nilai mendekatai atau sama dengan nol (Persamaan 3).

(a) Linear Monotonically Increasing

$$
S_{s t d_{x, y}}=\frac{S_{i_{x, y}}-S_{\min _{x, y}}}{S_{\max _{x, y}}-S_{\min _{x, y}}}
$$

(b) Linear Monotonically Decreasing

$$
S_{s t d_{x, y}}=\frac{S_{\max _{x, y}}-S_{i_{x, y}}}{S_{\max _{x, y}}-S_{\min _{x, y}}}
$$

$$
\begin{array}{ll}
S_{s t d_{x, y}} & =\text { nilai normalisasi pada sel }(\mathrm{x}, \mathrm{y}) \\
S_{i_{x y}} & =\text { skore kesesuaian / nilai jarak pada sel }(\mathrm{x}, \mathrm{y}) . \\
S_{\text {max }_{x, y}} & =\text { nilai maksimum jarak atau skore kesesuaian }
\end{array}
$$

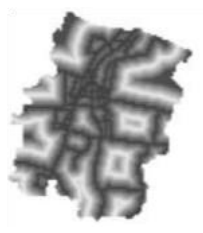

Jarak terhadap Jalan primer

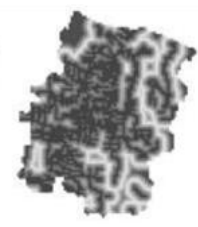

Jarak terhadap jalan sekunder

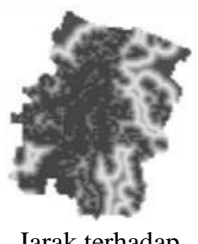

Jarak terhadap permukiman

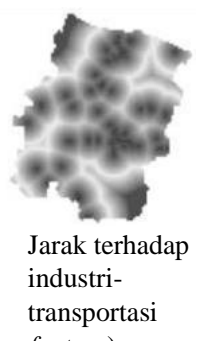

industri-
Gambar 1. Peta Jarak sebagai faktor pendorong (driving-factors)

Peta transisi yang digunakan pada penelitian ini ditujukan untuk pertumbuhan wilayah Industri-transportasi dan Permukiman. Adapun bobot yang digunakan dalam pembentukan peta transisi untuk perkembangan penggunaan lahan industri-transportasi adalah kedekatan terhadap industritransportasi eksisting (0.45), kedekatan terhadap jaringan jalan primer (0.35) dan kedekatan terhadap jaringan jalan sekunder (0.2).

Sedangkan untuk perkembangan permukiman adalah kedekatan terhadap jaringan jalan primer (0.2), kedekatan terhadap jaringan jalan sekunder (0.4) dan kedekatan terhadap permukiman eksisting (0.4). Pertimbangan bobot tersebut diputuskan berdasarkan asumsi, adapun untuk lebih baik dapat digunakan pendekatan AHP (Analytical Hierarchical Process) (26), dengan bobot berasal dari pendapat beberapa expert.

\section{B. Ekspektasi Pertumbuhan Penggunaan Lahan}

Proses Cellular Automata dengan menggunakan LanduseSim membutuhkan peta transisi untuk setiap pertumbuhan penggunaan lahan. Dalam kasus ini, dua kelas penggunaan lahan telah dipilih untuk diharapkan tumbuh yaitu pemukiman dan industri-transportasi (lihat pada Tabel 3). Sel pertumbuhan untuk kelas-kelas tersebut hanyalah data hipotetis yang digunakan sebagai instrumen untuk memproses prediksi pertumbuhan dalam penelitian ini. Namun, dalam kasus prediksi tren/kecenderungan, jumlah sel pertumbuhan dapat dihasilkan dari perbandingan peta penggunaan lahan dua tahun atau lebih secara berurutan. Pada kasus target besaran pertumbuhan dapat dihasilkan melalui dokumen perencanaan, keputusan dari pemerintah daerah, ataupun focus group discussion. Setiap kelas penggunaan lahan memiliki kendala penggunaan lahan sendiri untuk dikembangkan, yang berarti penggunaan lahan tidak akan pernah berkembang atau mengkonversi lahan batasan pembatasnya (lihat Tabel 1).

Pada aplikasi LanduseSim, cellular automata diproses dengan data penggunaan lahan yang telah ditetapkan sebagai peta awal simulasi dalah penelitian ini adalah peta penggunaan lahan Pekalongan tahun 2003. Kemudian peta tersebut diiterasi hingga 10 tahun kedepan untuk menciptakan peta penggunaan lahan tahun 2013 (Gambar 2). Neighborhood filter yang digunakan adalah $3 \times 3$ dengan proses penjumlahan pada file transisinya.

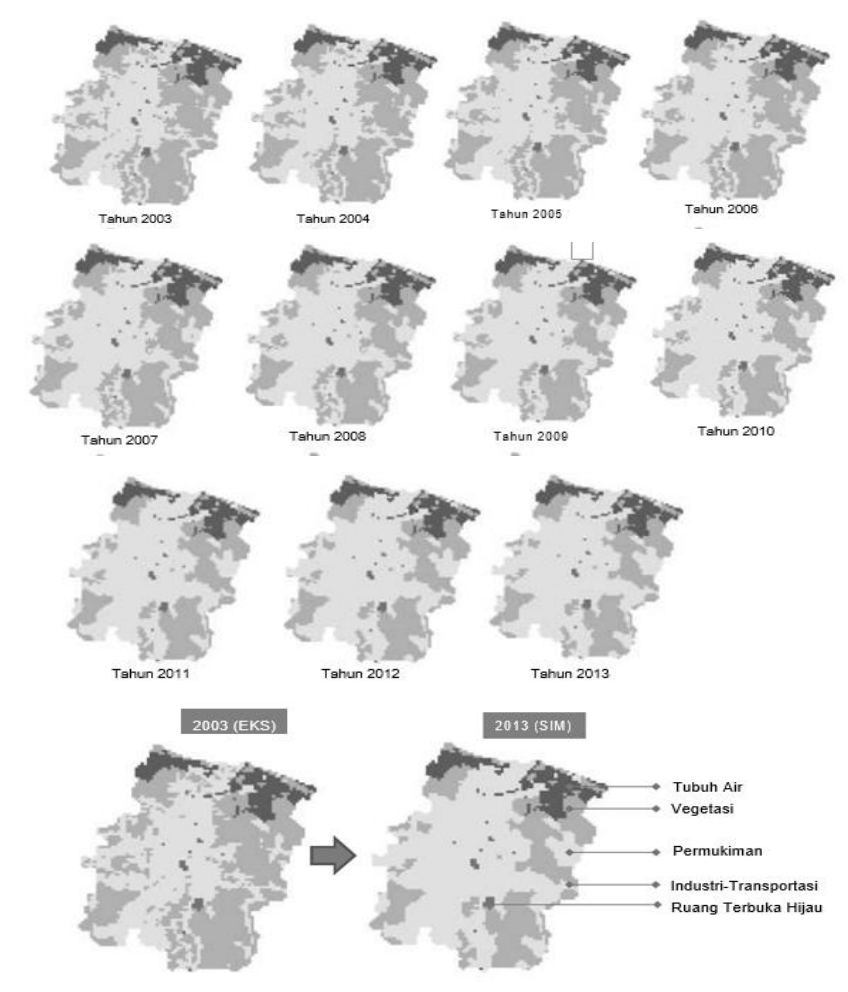

Gambar 2. Peta proses dan hasil simulasi perkembangan penggunaan lahan 2003-2013 
Tabel 2.

Peralihan Perubahan Penggunaan Lahan Hasil Simulasi Spasial

\begin{tabular}{|c|c|c|c|c|c|c|c|c|c|c|c|c|}
\hline $\begin{array}{l}\text { Penggunaan } \\
\text { Lahan }\end{array}$ & Code & 2003 & 2004 & 2005 & 2006 & 2007 & 2008 & 2009 & 2010 & 2011 & 2012 & 2013 \\
\hline $\begin{array}{l}\text { Industri- } \\
\text { Transportasi } \\
\text { Ruang }\end{array}$ & 1 & 94 & 99 & 104 & 109 & 114 & 119 & 124 & 129 & 134 & 139 & 144 \\
\hline Terbuka Hijau & 2 & 32 & 32 & 32 & 32 & 32 & 32 & 32 & 32 & 32 & 32 & 32 \\
\hline Tubuh Air & 3 & 400 & 400 & 400 & 400 & 400 & 400 & 400 & 400 & 400 & 400 & 400 \\
\hline Vegetasi & 4 & 2154 & 2084 & 2014 & 1943 & 1873 & 1803 & 1733 & 1663 & 1593 & 1523 & 1453 \\
\hline Permukiman & 5 & 1976 & 2041 & 2106 & 2172 & 2237 & 2302 & 2367 & 2432 & 2497 & 2562 & 2627 \\
\hline
\end{tabular}

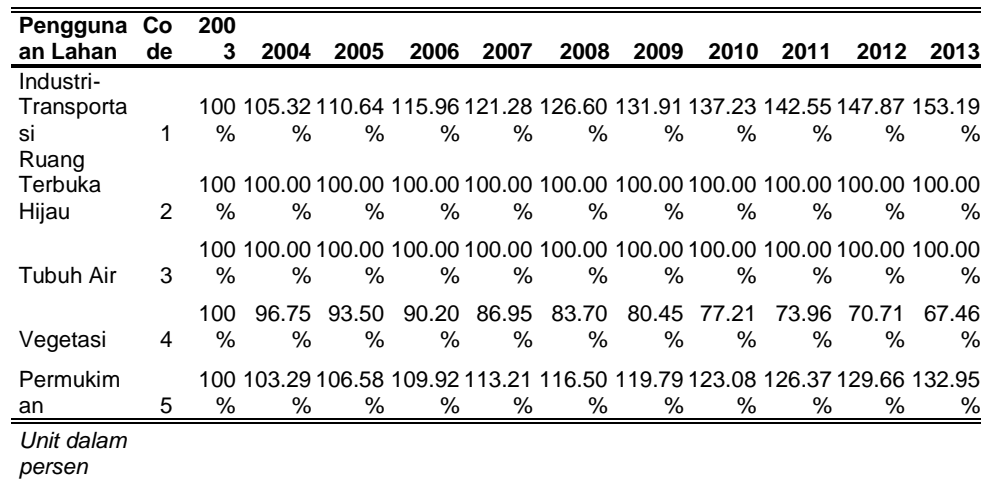

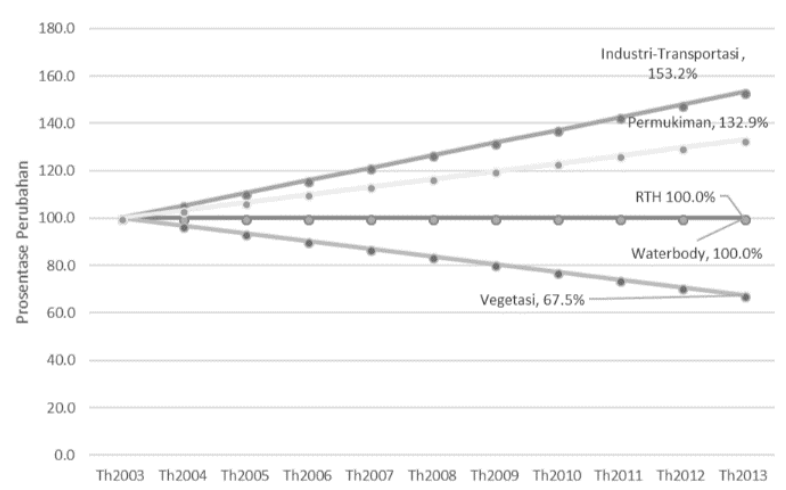

Gambar 3. Grafik dinamika perubahan lahan di wilayah studi 2003-2013

\section{KESIMPULAN DAN SARAN}

LanduseSim sebagai software pemodelan spasial sangat mampu melakukan simulasi spasial perubahan lahan. Selain itu LanduseSim mampu menunjukkan tingkat akurasi tinggi dengan pendekatan trend atau kecendrungan sebagaimana ditunjukkan Nugroho (21) sebesar 89\% dan Garbia dkk (11) sebesar $87-89 \%$. Dengan kemampuan prediksi berbasis target (pada penelitian ini) atau dengan trend, menunjukkan LanduseSim sangat sesuai untuk kegiatan perencanaan wilayah dan kota, seperti penyusunan dokumen tata ruang wilayah,

review tata ruang, sinkronisasi program pembangunan, alokasi pembiayaan daerah untuk pembangunan bertahap, pemilihan prioritas pembangunan infrastruktur dan lainnya. Dengan kemampuan LanduseSim, perencana semakin yakin terhadap rencana yang dihasilkan terutama menetapkan rencana pada masa perencanaan 10 hingga 20 tahun kedepan, dan terutama berimplikasi pada peningkatan kualitas perencanaan tata ruang yang dihasilkan.

Selain itu, kritikan pada pemodelan yang dilakukan bahwa pemodelan spasial perubahan lahan dengan pendekatan Cellular Automata dapat dilakukan dengan data resolusi rendah. Namun hasilnya lebih kompak dan kurang tersebar, sehingga sangat sulit untuk memberikan arahan yang cukup detail. Sebaliknya dengan data raster ukuran rendah, proses simulasi yang dilakukan lebih cepat. Untuk tataran studi explorasi dengan tingkat kedetailan rendah hingga cukup, penggunaan data resolusi rendah masih layak digunakan. Akan tetapi, untuk studi yang membutuhkan resolusi cukup-tinggi untuk menghasilkan arahan seperti arahan pola ruang, maka penggunaan input resolusi menengah ke atas diperlukan agar simulasi yang dihasilkan lebih baik. Untuk mendukung pernyataan tersebut, maka direkomendasikan untuk melakukan kajian terhadap implementasi simulasi pemodelan penggunaan lahan dengan tingkat resolusi rendah (100 meter hingga $1 \mathrm{Km})$ dikomparasi dengan tingkat resolusi tinggi (resolusi 10 meter hingga 30 meter).

Cellular automata sebagai teknik simulasi spasial dibutuhkan perencana untuk mengevaluasi rencana tata ruang baik dari segi struktur maupun pola ruang. Dengan memanfaatkan CA, perencana tidak hanya memutuskan berdasarkan skenario tunggal saja, melainkan multi-skenario yang dievaluasi dengan tujuan untuk mendapatkan kemungkinan terbaik di masa depan (1). Selain itu, penggunaan multi-skenario dibutuhkan oleh perencana dalam memformulasikan pembangunan berkelanjutan (13). Analisis skenario sangat cocok untuk studi jangka panjang yang berhubungan dengan kemungkinan pembangunan dan ketidakpastian. Skenario juga mampu menggambarkan beberapa pandangan alternatif masa depan serta memberikan gambaran penuh terhadap suatu potensi perubahan penggunaan lahan.

\section{DAFTAR PUSTAKA}

[1] Adhvaryu, B. 2010. Enhancing urban planning using simplified models: SIMPLAN for Ahmedabad, India. Progress in Planning, 73, 113207.

[2] Batty, M. 1997. Cellular automata and urban form: a primer, Journal of the American Planning Association, 63(2), 266-274.

[3] Batty, M., Xie, Y., Sun, Z. 1999. Modeling urban dynamics through GIS-based cellular automata. Computers, Environments and Urban Systems, 23, 205-233.

[4] Barredo,J., Kasanko, M., McCormick, M., Lavalle, C. 2003. Modelling dynamic spatial processes: Simulation of urban future scenarios through cellular automata. Landscape and Urban Planning, 64, 145-160.

[5] Barredo, J.I., Demicheli, L., Lavalle, C., Kasanko, M., McCormick, N. 2004. Modelling future urban scenarios in developing countries: An application case study in Lagos, Nigeria. Environment and Plannning B, 31, 65-84.

[6] Chen, J., Gong, P., He, C., Luo, W., Tamura, M., Shi, P. 2002. Assessment of the urban development plan Beijing by using a CA-based urban growth model. Photogrammetric Engineering \& Remote Sensing, 68, 1063-1071.

[7] Clarke, K.C., Hoppen, C. Gaydos, L. 1997. A self-modifying cellular automaton model of historical urbanisation in the San Francisco Bay Area, Environment and Planning B, 24, 247-261.

[8] Engelen, G., 1988. The theory of self-organization and modeling complex urban system. Eur. J. Oper. Res, 37, 42-57.

[9] Engelen, G., Geertman, S., Smits, P., Wessels, C. 1999. Dynamic GIS and strategic physical planning support: a practical application, Chapter 5 in Stillwell, J.C.H., Geertman, S. and Openshaw, S. (eds) Geographical Information and Planning, Springer, Berlin, 87-111. 
[10] Fuglsang, M., Munier, B., Hansen, HS. 2013. Modelling land-use effects of future urbanization using cellular automata: An Eastern Danish case. Environmental Modelling \& Software, 50, 1-11.

[11] Gharbia, S.S., Alfatah, S.A., Gill, L. et al. 2016. Land use scenarios and projections simulation using an integrated GIS cellular automata algorithms. Model. Earth Syst. Environ. (2016) 2: 151. https://doi.org/10.1007/s40808-016-0210-y

[12] Hall, P. 2002. Urban and Regional Planning Fourth Edition, Routledge. He, C., Okada, N., Zhang, Q., Shi, P., Li, J. 2008. Modelling dynamic urban expansion processes incorporating a potential model with cellular automata. Landscape and Urban Planning, 86, 79-91.

[13] Itami, R.M. 1994. Simulating spatial dynamics: cellular automata theory. Landscape and Urban Planning, 30, 24-47.

[14] Lambin, E.F., Geisth, H. 2001. Global land use and land cover change: What have learn so far?. Global Change News Letter, 46, 27-30.

[15] Li, X. and Yeh, A.G.O. 2000. Modelling sustainable urban development by the integration of constrained cellular automata and GIS, International Journal of Geographical Information Science, 14(2), 131-152.

[16] Li, X. and Yeh, A.G.O. 2004. Data mining of cellular automata's transition rules. International Journal Geograhpical Information Science, $18,723-744$.

[17] MacGill, S.M. 1986. Evaluating a heritage of modelling styles. Environmental and Planning A, 18, 1423-1446.

[18] Marfai, M.A., Pratomoatmojo, N.A., Hidayatullah, T., Nirwansyah, A.W., \& Gomaeruzzaman, M. 2011. Model Kerentanan Wilayah Pesisir Berdasarkan Perubahan Garis Pantai dan Banjir Pasang (Studi Kasus: Wilayah Pesisir Pekalongan). RedCarpet Studio. Yogyakarta

[19] Mitsova, D., Shuster, W., Wang, X. 2011. A cellular automata model of land cover change to integrate urban growth with open space conservation. Landscape and Urban Planning, 99, 141-153.

[20] Nugroho, A.A. 2013. Model Perubahan Landuse akibat kenaikan muka air laut dan pasang maksimum di pantai utara teluk lamong (PUTL) bagian surabaya. Master Tesis Teknik Manajemen Pantai ITS. Indonesia

[21] Pratomoatmojo, N.A. 2014. LanduseSim sebagai aplikasi pemodelan dan simulasi spasial perubahan penggunaan lahan berbasis Sistem Informasi Geografis dalam konteks perencanaan wilayah dan kota. Seminar Nasional CITIES 2014. ISBN : 978-602-71612-0-7

[22] Pratomoatmojo, N.A. 2012. Land use change modelling under tidal flood scenario by means of Markov-Cellular Automata in Pekalongan Municipal. Universitas Gadjah Mada, Yogyakarta.

[23] Rutledge, D. 2003. Landscape indices as Measures of the Effect of Fragmentation: Can Pattern Reflect Process?. DOC Sci. Intern. Ser. 98, pp. 1-27, 2003.

[24] Sante I., Garcia, A.M., Miranda, D., Crecente, R. 2010. Cellular automata models for the simulation of real-world urban processes: A review and analysis. Landscape and Urban Planning, 96, 108-122.

[25] Satty, T.L. 1980. The analytic hierarchy process. McGraw-Hill, New York.

[26] Thomas, H., Laurence, H.M. 2006. Modelling and projecting land- use and land-cover changes with a cellular automaton in considering landscape trajectories: an improvement for simulation of plausible future states. EARSeL eProceedings 5, 63-76.

[27] Tobler, W. R. 1979. Cellular geography, in Gale, S. and Olsson, G. (eds) Philosophy in Geography, Reidel, Dordrectht, 379-386.

[28] Verburg, P.H., Veldkamp, W.S.A., Espaldon, R.L.V., Mastura, S.S.A. 2002. Modeling the spatial dynamics of regional land use: The CLUE-S Model. Environmental Management, 30, 391-405.

[29] Wijaya, A., Susetyo, C., Diny, A.Q., Nabila, D.H., Pamungkas, R.P., Hadikunnuha, M., and Pratomoatmojo, N.A. 2017.

[30] Spatial Pattern Dynamics Analysis at Coastal Area Using Spatial Metric in Pekalongan, Indonesia. doi:10.20944/preprints201705.01 45.v1

[31] Wolfram, S. 1984. Cellular automata as models of complexity, Nature, $311,419-424$.

[32] Xue, F. and Bian, Z. 2008. GIS combined with MCE to evaluate land quality. Agriculture, IFIP International Federation for Information Processing, Volume 258; Computer And Computing Technologies, 1, 215-222. 